\title{
The catechol estrogen, 4-hydroxyestrone, has tissue-specific estrogen actions
}

\author{
K C Westerlind, K J Gibson, G L Evans ${ }^{1}$ and R T Turner ${ }^{1}$ \\ AMC Cancer Research Center, Denver, Colorado 80214, USA \\ ${ }^{1}$ Mayo Clinic, Rochester, Minnesota 55905, USA \\ (Requests for offprints should be addressed to K C Westerlind, AMC Cancer Research Center, 1600 Pierce Street, Denver, Colorado 80214, USA; \\ Email: westerlind@amc.org)
}

\begin{abstract}
Recent data indicate that the catechol estrogen, 2-hydroxyestrone $\left(2-\mathrm{OHE}_{1}\right)$, has no effect on any target tissue including bone, whereas 16 $\alpha$-hydroxyestrone $\left(16 \alpha-\mathrm{OHE}_{1}\right)$ exerts tissue-selective estrogen agonist activity. The effect of the catechol estrogen, 4hydroxyestrone $\left(4-\mathrm{OHE}_{1}\right)$, putatively associated with tumorigenesis, has not been studied in the skeleton. The purpose of this study was to assess the effect of $4-\mathrm{OHE}_{1}$ on tibia, uterine and mammary gland histology and blood cholesterol in ovariectomized (OVX'd) growing rats. Ten-week-old female Sprague-Dawley rats were injected subcutaneously with $200 \mu \mathrm{g} / \mathrm{kg}$ BW per day with $4-\mathrm{OHE}_{1}, 17 \beta$-estradiol $\left(\mathrm{E}_{2}\right)$ or vehicle for three weeks. OVX resulted in uterine atrophy, increased body weight, radial bone growth and cancellous bone turnover, and hypercholesterolemia. $E_{2}$ prevented these changes with the expected exception that the subcutaneous infusion of this high dose of estrogen did not prevent the
\end{abstract}

hypercholesterolemia. 4- $\mathrm{OHE}_{1}$ prevented the increase in blood cholesterol and the increase in body weight. 4-OHE ${ }_{1}$ appeared to have partial estrogen activity in the uterus; uterine weight and epithelial cell height were significantly greater than the OVX rats but significantly less (twofold) than the $\mathrm{E}_{2}$ animals. Analysis of variance indicated that $4-\mathrm{OHE}_{1}$ slightly decreased the periosteal mineral apposition rate $(P<0 \cdot 05)$ compared with vehicletreated rats but had no effect on double-labeled perimeter or bone formation rate. Similarly, $4-\mathrm{OHE}_{1}$ was a partial estrogen agonist on cancellous bone turnover. The data suggest that the catechol estrogen, 4-OHE ${ }_{1}$, unlike $2-\mathrm{OHE}_{1}$, has estrogen activity. Furthermore, the profile of activity differs from that of $16 \alpha-\mathrm{OHE}_{1}$. Our results suggest that estrogen metabolites may selectively influence estrogen-target tissues and, concomitantly, modulate estrogen-associated disease risk.

Journal of Endocrinology (2000) 167, 281-287

\section{Introduction}

The presence or absence of estrogens are implicated in the etiology and pathogenesis of multiple diseases including breast and reproductive cancers, osteoporosis, and coronary heart disease. Current investigations are underway to evaluate their role in Alzheimer's, stroke, and cancers of the colon and prostate.

Early evidence has suggested that breakdown of estradiol and estrone to their metabolites $(2,4,16 \alpha-$ hydroxyestradiol and 2,4,16 $\alpha$-hydroxyestrone) may be indicative of risk of disease. For example, it has been observed that increased 2-hydroxylation of estrone to the catechol estrogen, 2-hydroxyestrone (2-OHE 1 ), confers decreased risk for breast (Ho et al. 1998, Meilahn et al. 1998) and cervical cancer (Sepkovic et al. 1995) but may be associated with an increased risk for osteoporosis (Hodge et al. 1995, Lim et al. 1997). Conversely, elevated $16 \alpha$-hydroxylation to $16 \alpha$-hydroxyestrone $\left(16 \alpha-\mathrm{OHE}_{1}\right)$ has been associated with increased risk for breast cancer
(Schneider et al. 1982, Osborne et al. 1993, Kabat et al. 1997) but decreased risk for osteoporosis (Lim et al. 1997). Although these hypotheses are not proven, it is evident that the estrogen metabolites are not breakdown products without biological activity but rather have specific and differential activities in estrogen-sensitive tissues.

In this vein, this lab recently evaluated the effect of $2-$ and $16 \alpha-\mathrm{OHE}_{1}$ on estrogen-responsive tissues including the uterus, liver, mammary gland and bone in the ovariectomized rat (Westerlind et al. 1998). The catechol estrogen, 2-OHE 1 , had no estrogen activity on any target tissue evaluated. In contrast, $16 \alpha-\mathrm{OHE}_{1}$ acted as a full estrogen agonist on the bone and liver and a partial estrogen agonist on the uterus and mammary gland. In this regard, this endogenous estrogen resulted in similar effects to those seen with anti-estrogens such as tamoxifen and raloxifene (Evans et al. 1994, Ke et al. 1995, Evans et al. 1996, Turner et al. 1988).

Although not the predominant pathway in humans, estradiol and estrone are also hydroxylated at the C-4 
position to form the catechol estrogens, 4-hydroxyestradiol $\left(4-\mathrm{OHE}_{2}\right)$ and 4-hydroxyestrone $\left(4-\mathrm{OHE}_{1}\right)$ respectively (Ball \& Knuppen 1980). These metabolites have been shown to be tumorigenic in animal models (Liehr 1994, Yager \& Liehr 1996) as they undergo metabolic redox cycling to generate free radicals and unstable adducts capable of removing purines from DNA and potentiating the misrepair of important genes. Thus, although it is generally accepted that certain estrogen metabolites increase cell proliferation and are associated with cancer promotion and progression, it is also speculated that some estrogen metabolites may be associated with cancer initiation.

To date, the effect of $4-\mathrm{OHE}_{1}$ on other estrogensensitive tissues has not been thoroughly evaluated. The purpose of the present investigation was to characterize the response of the uterus, mammary gland, liver and bone to $4-\mathrm{OHE}_{1}$ treatment in the ovariectomized rat model. This study would complement those data from earlier work and would extend our understanding of the relative estrogenicity of three important estrogen metabolites in multiple tissues.

\section{Materials and Methods}

Fifty female Sprague-Dawley rats were obtained from Taconic Farms (Germantown, NY, USA) at approximately 9 weeks of age (mean $\mathrm{BW}=170 \pm 2 \mathrm{~g}$ ). Bilateral ovariectomy $(\mathrm{OVX})(n=40)$ or sham surgery $(n=10$; Intact) was performed at the vendor 2-3 days prior to shipment. Upon arrival and following acclimation to the facilities, the 40 OVX animals were stratified by weight and randomly assigned to four groups $(n=10$ for each group), consisting of a baseline or one of three treatment groups: $4-\mathrm{OHE}_{1}, 17 \beta$-estradiol $\left(\mathrm{E}_{2}\right)$ or vehicle (OVX).

Treatment was not started until 1 week post-OVX to allow for estrogen levels to become depleted. Treatment consisted of daily subcutaneous injections of $4-\mathrm{OHE}_{1}$, $17 \beta-\mathrm{E}_{2}$ or vehicle $(50 \%$ ethanol). The dose was set at $200 \mu \mathrm{g} / \mathrm{kg} \mathrm{BW}$ based on an initial mean group body weight of $180 \mathrm{~g}$ and was not altered over the 3-week treatment period. This dose was chosen because it had been used in the previous study with $2-$ and $16-\mathrm{OHE}_{1}$ and would ensure saturation of estrogen receptors. $4-\mathrm{OHE}_{1}$ and $17 \beta-E_{2}$ were obtained from Sigma Chemical Co. (St Louis, MO, USA) and mixed to appropriate concentrations in the vehicle. Ascorbic acid $(1 \mathrm{mg} / \mathrm{ml})$ was added to the preparation of $4-\mathrm{OHE}_{1}$ to prevent oxidation of the labile metabolite. No ascorbic acid was added to the vehicle or $E_{2}$ solution. To further maintain biological activity, solutions were aliquoted to individual vials for daily injections and frozen at $-80{ }^{\circ} \mathrm{C}$ until use. All animals were injected with $200 \mu \mathrm{l}$ of the individual treatment at 08:00 daily. Treatment duration was 3 weeks.

Fluorochromes to label mineralizing bone matrix were administered by juxta-tail vein injection 1 day before starting the treatment period (tetracycline- $\mathrm{HCl}, 20 \mathrm{mg} / \mathrm{kg}$ of BW; Sigma), 7 days before sacrifice (calcein, $20 \mathrm{mg} / \mathrm{kg}$ of BW; Sigma), and 1 day before sacrifice (tetracycline, as described). The two fluorochome labels are readily differentiated under u.v. illumination, because tetracycline fluoresces pale yellow, while calcein fluoresces bright green. Animals were injected i.p. with bromodeoxyuridine, in $0.9 \% \mathrm{NaCl}$ ((BRDU); $50 \mathrm{mg} / \mathrm{kg} \mathrm{BW}) 3 \mathrm{~h}$ prior to sacrifice to label cells in S-phase.

Animals were sacrificed by $\mathrm{CO}_{2}$ inhalation $24 \mathrm{~h}$ after their last treatment injection. Baseline animals were sacrificed on the day that treatment was started. Blood was collected via the peri-orbital route for measurement of serum cholesterol. The uterus was excised for wet weight determination and for measurement of epithelial cell height. Mammary glands were excised for histological evaluation and BRDU immunohistochemistry quantitation. The right tibia was removed and fixed in $70 \%$ ethanol for static and dynamic histomorphometry.

\section{Uterus}

The uterus was weighed for an initial wet weight and then fixed in 10\% neutral buffered formalin for $4-6 \mathrm{~h}$, then transferred to $70 \%$ ethanol until processing for conventional paraffin embedding. Sections $(5 \mu \mathrm{m})$ were cut and stained with hematoxylin and eosin (H\&E) to measure epithelial height. Uterine epithelial height, expressed in $\mu \mathrm{m}$, was measured at $\times 40$ with a Cell Analysis System (Chicago, IL, USA). A minimum of 50 sites were measured from each section/animal.

\section{Mammary glands}

The right and left mammary gland chains were removed. Lymph node regions were removed and fixed in 10\% neutral buffered formalin and Methacarn. These regions were used for histological evaluation with standard H\&E staining and BRDU immunohistochemistry respectively.

Mammary glands fixed in Methacarn were embedded in paraffin and sectioned at $5 \mu \mathrm{m}$. Sections were deparaffinized in a series of xylenes, hydrated through descending grades of ethanol, rinsed in deionized water and denatured in $2 \mathrm{~N} \mathrm{HCl}$ for $90 \mathrm{~min}$. After rinsing, sections were placed in $0 \cdot 1 \mathrm{M}$ sodium tetraborate for $5 \mathrm{~min}$, then rinsed again in deionized water. The endogenous peroxidase activity was blocked with $3 \% \mathrm{H}_{2} \mathrm{O}_{2}$ and followed with another rinse in PBS. The primary antibody, Mouse anti-BrdU (1:40) (Becton-Dickinson, San Diego, CA, USA) was applied followed by three rinses in PBS. Sections were incubated for 30 min with biotinylated Rabbit anti-Mouse (1:200) (Dako, Carpinteria, CA, USA) in 10\% Normal Rabbit Serum. Sections were then incubated with conjugated HRP streptavadin (1:1000) (Dako) then rinsed in PBS. Diaminobenzidine (DAB) (Sigma) in $0.4 \% \mathrm{H}_{2} \mathrm{O}_{2}$ was applied for $10 \mathrm{~min}$ and sections were rinsed in deionized 
water and counterstained with Harris Hematoxylin and blued with Scotts $\mathrm{H}_{2} \mathrm{O}$. Sections were dehydrated through ascending grades of ethanol, cleared in xylene, and mounted with Permount (Fisher, Pittsburgh, PA, USA).

Computer-generated random numbers provided coordinates for measurement of BRDU incorporation. Twenty high powered fields were identified each for ductal and lobular structures. Cells that incorporated BRDU, as identified by brown pigment over the nuclei and along the nuclear membrane, were counted and expressed as a percentage of the area measured. The reviewer was blinded to group assignment.

\section{Serum cholesterol}

Blood samples were allowed to clot at room temperature for $2 \mathrm{~h}$ and serum was obtained after centrifugation at 2000 r.p.m. for $15 \mathrm{~min}$. Serum samples were stored at $-80{ }^{\circ} \mathrm{C}$ until analysis. Serum cholesterol was determined using a Cobas-Mira high performance cholesterol assay (Branchburg, NJ, USA) with Roche Reagents (Mannheim, Germany). Briefly, serum cholesterol is released from its esters by enzymatic action of an ester hydrolase and then oxidized by cholesterol oxidase to produce hydrogen peroxide. The hydrogen peroxide, when combined with 4-aminoantipyrine and phenol, forms a chromophore which is visible at $500 \mathrm{~nm}$ and is directly proportional to the cholesterol concentration.

\section{Bone histomorphometry}

Histomorphometric measurements were performed with an Osteomeasure semi-automatic image analysis system (Osteomeasure, Atlanta, GA, USA) which has been described in detail (Jiminez et al. 1997).

\section{Longitudinal growth rate}

Longitudinal growth rate was measured in the proximal tibial metaphysis and is the mean distance between the calcein labeling front located in the primary and secondary spongiosa and the final tetracycline label in the mineralizing growth plate cartilage divided by the labeling interval of 6 days.

\section{Cortical bone measurements}

Ground transverse sections were used for histomorphometric analysis of cortical bone. Cross-sections $150 \mu \mathrm{m}$ thick were cut at a site just proximal to the tibia-fibula synostosis with a low speed saw (Isomet, Buehler, Lake Bluff, IL, USA) equipped with a diamond wafer blade. The sections were ground to a thickness of $20 \mu \mathrm{m}$ on a roughened glass plate and mounted in glycerin before microscopic examination under u.v. illumination to visualize fluorochrome labeling. The following measure- ments were performed on the undemineralized sections as described (Jiminez et al. 1997): (1) cross-sectional area, defined as the area of bone and marrow cavity bounded by the periosteal surface of the specimen, (2) medullary area, defined as the area delineated by the endocortical surface of the specimen, (3) cortical bone area, calculated as the difference between the cross-sectional and medullary area, (4) periosteal perimeter, defined as the total perimeter enclosing the cross-section (periosteal perimeter includes fluorochrome-labeled and nonlabeled perimeters), (5) periosteal bone formation rate, calculated as the area bounded by the tetracycline labels and divided by the labeling period of 21 days, and (6) periosteal mineral apposition rate, defined as the periosteal bone formation rate divided by the label perimeter.

\section{Cancellous bone measurements}

The tibia was dehydrated in a series of increasing concentrations of ethanol, embedded without demineralization in a mixture of methylmethacrylate-2-hydroxyethylmethacrylate $(12 \cdot 5: 1)$ to retain the fluorochrome labels, and sectioned at a thickness of $5 \mu \mathrm{m}$.

The sampling site included the entire tibial epiphysis and represented an area approximately $2 \cdot 8 \mathrm{~mm}^{2}$. Measurements were performed as described previously (Jiminez et al. 1997). Cancellous bone area was determined as the area of total cancellous bone per $\mathrm{mm}^{2}$ epiphyseal area and expressed as a percentage. Cancellous bone perimeter was determined as the perimeter of cancellous bone perimeter per $\mathrm{mm}^{2}$ epiphyseal area. Bone formation rate was calculated as the product of the double label perimeter and mineral apposition rate. The mineral apposition rate, expressed in $\mu \mathrm{m} /$ day was the mean distance between the calcein and second tetracycline label divided by the labeling interval of 6 days. Double-labeled perimeter was determined as the bone perimeter with the calcein and second tetracycline labels. The data were expressed in three-dimensional units following multiplication by unit thickness.

\section{Statistical analysis}

Analyses of variance were performed on all variables. Student-Neuman-Keuls post hoc multiple comparison tests were performed to assess between-group differences when appropriate. A $P$ value of $<0 \cdot 05$ was designated as statistically significant.

\section{Results}

The effects of OVX, $\mathrm{E}_{2}$ and $4-\mathrm{OHE}_{1}$ on body weight, serum cholesterol, and longitudinal growth rate are presented in Table 1. All of the treatment groups had an increase in body weight compared with baseline values. 
Table 1 Effects of OVX, $17 \beta$-estradiol and $4-\mathrm{OHE}_{1}$ on body weight, serum cholesterol and longitudinal growth rate at the proximal tibial metaphysis. Values are means \pm S.E.M.

\begin{tabular}{|c|c|c|c|c|c|}
\hline & Baseline & Intact & OVX-vehicle & $17 \beta$-estradiol & 4-OHE 1 \\
\hline Initial weight (g) & $170 \cdot 7 \pm 2 \cdot 3$ & $170 \cdot 3 \pm 2 \cdot 9$ & $170 \cdot 8 \pm 2 \cdot 0$ & $170 \cdot 3 \pm 2 \cdot 7$ & $170 \cdot 0 \pm 1 \cdot 8$ \\
\hline Growth rate (g/day) & & $2 \cdot 1 \pm 0 \cdot 2^{\star}$ & $4 \cdot 0 \pm 0 \cdot 3^{\dagger}$ & $1 \cdot 5 \pm 0 \cdot 2^{* \dagger}$ & $2 \cdot 4 \pm 0 \cdot 2^{*}$ \\
\hline Cholesterol (mg/dl) & & $92 \cdot 4 \pm 4 \cdot 8^{*}$ & $111 \cdot 7 \pm 4 \cdot 7^{\dagger}$ & $129 \cdot 3 \pm 5 \cdot 9^{* \dagger}$ & $98 \cdot 6 \pm 6 \cdot 2^{*}$ \\
\hline Longitudinal growth rate ( $\mu \mathrm{m} /$ day) & & $76 \pm 7^{*}$ & $142 \pm 10^{\dagger}$ & $60 \pm 8^{*}$ & $101 \pm 3^{* \dagger}$ \\
\hline
\end{tabular}

*Significantly different $(P \leq 0.05)$ from the OVX-vehicle group.

${ }^{\dagger}$ Significantly different $(P \leq 0 \cdot 05)$ from the intact group.

OVX resulted in significant increases in body weight, serum cholesterol and longitudinal growth rate relative to the intact animals. $E_{2}$ prevented the OVX-induced weight gain and increase in longitudinal growth rate and resulted in values not different from the intact group. Serum cholesterol was elevated by treatment with $\mathrm{E}_{2}$ to levels significantly greater than the OVX and intact animals. Treatment with 4-OHE 1 halted the OVX-induced body weight gain and serum cholesterol increase; values were not significantly different from the intact group. The increase in longitudinal growth rate was attenuated in the 4- $\mathrm{OHE}_{1}$ treated animals to a level intermediate between the OVX and intact animals.

Uterine wet weight and epithelial height data are presented in Table 2. OVX resulted in significant decreases in wet weight and epithelial height relative to the intact group. $\mathrm{E}_{2}$ treatment resulted in uterine weights and epithelial height significantly greater than the OVX and intact animals. $4-\mathrm{OHE}_{1}$ treatment resulted in uterine wet weights that were significantly greater than the OVX group but significantly less than those of the intact animals. Also, epithelial heights were significantly greater than OVX but not different from those of the intact animals. All 4-OHE 1 uterine values were significantly less than the $\mathrm{E}_{2}$ treatment (not signified in Table 2).

BRDU labeling of lobular and ductal units from the lymph node region of the mammary gland (Table 2) indicated a significant increase as a result of $\mathrm{E}_{2}$ treatment relative to OVX. No increase was observed with $4-\mathrm{OHE}_{1}$ relative to the OVX group. Data from the intact animals were not included due to the variability in labeling associated with the normal estrous cycle.

Cortical bone histomorphometry data are shown in Table 3. As expected in a short-term study, there were no significant differences in static bone measurements (crosssectional area, medullary area, cortical bone area, periosteal perimeter) among the intact, OVX or two estrogentreated groups. There was an age-related change in the four groups relative to the baseline animals in the crosssectional and cortical areas and in periosteal perimeter expansion. OVX resulted in an increase in periosteal bone formation rate and mineral apposition rate that was prevented by $\mathrm{E}_{2}$ treatment. 4-OHE $\mathrm{OH}_{1}$ did not result in a decrease in bone formation rate relative to the OVX although the mineral apposition rate was attenuated to a level intermediate between the OVX and intact animals.

The high rate of longitudinal growth precluded measurement of cancellous bone remodeling in the tibial metaphysis. The epiphysis, in contrast, is skeletally mature bone and is thus amenable to studying bone remodeling in the young animal model. Although OVX does not generally result in a loss of cancellous bone from the epiphysis, bone turnover is greatly increased at that site. Cancellous bone histomorphometry data are presented in Table 4. OVX resulted in a significant increase in bone formation rate, whether expressed relative to tissue

Table 2 Effects of OVX, $17 \beta$-estradiol and $4-\mathrm{OHE}_{1}$ on uterine weight, uterine epithelial height and BRDU labeling of mammary gland. Values are means \pm S.E.M.

\begin{tabular}{|c|c|c|c|c|}
\hline & Intact & OVX-vehicle & 17ß-estradiol & 4-OHE \\
\hline \multicolumn{5}{|l|}{ Measurement } \\
\hline \multicolumn{5}{|l|}{ Uterus } \\
\hline Uterine wet weight (g) & $0 \cdot 38 \pm 0 \cdot 02^{*}$ & $0 \cdot 10 \pm 0 \cdot 05^{\dagger}$ & $0.44 \pm 0.02^{* \dagger}$ & $0 \cdot 27 \pm 0 \cdot 01^{\star \dagger}$ \\
\hline \multicolumn{5}{|c|}{ Mammary gland - BRDU labeling } \\
\hline Ducts (\% area) & & $1 \cdot 24 \pm 0 \cdot 82$ & $3 \cdot 14 \pm 0 \cdot 90^{*}$ & $1 \cdot 59 \pm 0 \cdot 47$ \\
\hline
\end{tabular}

${ }^{*}$ Significantly different $(P \leq 0 \cdot 05)$ from the OVX-vehicle group.
${ }^{\dagger}$ Significantly different $(P \leq 0 \cdot 05)$ from the intact group. 
Table 3 Effects of OVX, $17 \beta$-estradiol and $4-\mathrm{OHE}_{1}$ on cortical bone histomorphometry. Values are means \pm S.E.M.

\begin{tabular}{|c|c|c|c|c|c|}
\hline & Baseline & Intact & OVX-vehicle & $17 \beta$-estradiol & 4-OHE \\
\hline \multicolumn{6}{|l|}{ Measurement } \\
\hline Cross-sectional area $\left(\mathrm{mm}^{2}\right)$ & $3 \cdot 21 \pm 0 \cdot 04$ & $3 \cdot 65 \pm 0.06^{*}$ & $3 \cdot 71 \pm 0 \cdot 07^{*}$ & $3 \cdot 55 \pm 0 \cdot 07^{*}$ & $3 \cdot 70 \pm 0 \cdot 10^{*}$ \\
\hline Medullary area $\left(\mathrm{mm}^{2}\right)$ & $0 \cdot 77 \pm 0 \cdot 03$ & $0 \cdot 70 \pm 0 \cdot 03$ & $0 \cdot 70 \pm 0 \cdot 03$ & $0.60 \pm 0.02$ & $0.79 \pm 0.05$ \\
\hline Cortical bone area $\left(\mathrm{mm}^{2}\right)$ & $2 \cdot 44 \pm 0 \cdot 04$ & $2 \cdot 95 \pm 0.05^{*}$ & $3 \cdot 02 \pm 0.05^{*}$ & $2 \cdot 92 \pm 0.05^{*}$ & $2 \cdot 91 \pm 0.07^{*}$ \\
\hline Periosteal perimeter (mm) & $6 \cdot 05 \pm 0.05$ & $6.97 \pm 0.07^{*}$ & $7 \cdot 07 \pm 0 \cdot 07^{*}$ & $6 \cdot 80 \pm 0.06^{* \dagger}$ & $7 \cdot 01 \pm 0 \cdot 09^{*}$ \\
\hline \multicolumn{6}{|l|}{ Periosteal bone formation rate } \\
\hline$\left(\mathrm{mm}^{2} \times 10^{-3} /\right.$ day $)$ & & $16 \cdot 62 \pm 0 \cdot 99^{\dagger}$ & $25 \cdot 92 \pm 1 \cdot 51^{\ddagger}$ & $19 \cdot 01 \pm 1 \cdot 51^{\dagger}$ & $23 \cdot 76 \pm 1 \cdot 23^{\ddagger}$ \\
\hline Mineral apposition rate $(\mu \mathrm{m} /$ day $)$ & & $2 \cdot 72 \pm 0 \cdot 11^{\dagger}$ & $3 \cdot 77 \pm 0 \cdot 21^{\ddagger}$ & $2 \cdot 91 \pm 0 \cdot 15^{\dagger}$ & $3 \cdot 32 \pm 0 \cdot 14^{\dagger \ddagger}$ \\
\hline
\end{tabular}

*Significantly different $(P \leq 0 \cdot 05)$ from the baseline group.

${ }^{+}$Significantly different $(P \leq 0.05)$ from the OVX-vehicle group.

${ }^{\text {ES}}$ Significantly different $(P \leq 0 \cdot 05)$ from the intact group.

volume, bone volume or bone surface. $\mathrm{E}_{2}$ treatment prevented the increases in the three indices of bone formation. 4- $\mathrm{OHE}_{1}$ mitigated the OVX-induced increase in the indices of formation but not as greatly as $E_{2}$ treatment. Bone volume was increased in both the $\mathrm{E}_{2}$ and 4-OHE $\mathrm{OH}_{1}$-treated groups, in all likelihood due to an inhibition of bone resorption. The mineral apposition rate was not significantly altered by OVX or any treatment. The surface covered by double labels was significantly increased with ovariectomy, was prevented in full by $\mathrm{E}_{2}$ treatment, and was partially prevented with $4-\mathrm{OHE}_{1}$.

\section{Discussion}

Ovariectomy resulted in the expected uterine and mammary gland atrophy while increasing body weight, serum cholesterol and indices of bone turnover (Wronski et al. 1986, 1988, Turner et al. 1987, Westerlind et al. 1993). $E_{2}$ treatment resulted in increases in uterine weight, mammary gland proliferation and serum cholesterol as has previously been documented (Westerlind et al. 1998). Likewise, $\mathrm{E}_{2}$ treatment arrested the OVX-induced acceleration in both longitudinal bone growth, radial bone growth and cancellous bone turnover (Westerlind et al. 1993, 1998). Serum cholesterol was increased in the $\mathrm{E}_{2}$-treated animals, a finding similar to that observed previously (Westerlind et al. 1998). Although not noted in human estrogen replacement studies, increases in cholesterol, due to dose and/or mode of administration, have been reported by other investigators in the rat model (Ke et al. 1995, Evans et al. 1996).

The catechol estrogen $4-\mathrm{OHE}_{1}$ had effects that were tissue specific. Serum cholesterol was markedly decreased in the $4-\mathrm{OHE}_{1}$ group and was not different from the intact animals. $4-\mathrm{OHE}_{1}$ was not as effective as $\mathrm{E}_{2}$ in stimulating uterine growth. Values were greater than the OVX animals and approximately $40 \%$ of those of the $E_{2}$ animals. This is consistent with earlier reports of the relative estrogen activity of the 4-hydroxyestrogens in reproductive tissues (Martucci 1983).

Qualitative mammary gland histology indicated significant lobular/alveolar development in the $4-\mathrm{OHE}_{1}$ group compared with the OVX animals. In several cases, the glands were indistinguishable from those found in the $\mathrm{E}_{2}$ group. This apparent increased proliferation is not however reflected in the BRDU quantitative immunohistochemistry. Animals had been treated for 3 weeks with

Table 4 Effects of OVX, 17ß-estradiol and $4-\mathrm{OHE}_{1}$ on cancellous bone histomorphometry in the tibial epiphysis. Values are means \pm S.E.M.

\begin{tabular}{|c|c|c|c|c|}
\hline & Intact & OVX-vehicle & $17 \beta$-estradiol & $4-\mathrm{OHE}_{1}$ \\
\hline \multicolumn{5}{|l|}{ Measurement } \\
\hline Bone volume/tissue volume (\%) & $34 \cdot 0 \pm 2 \cdot 3$ & $32 \cdot 4 \pm 3 \cdot 0$ & $43 \cdot 3 \pm 2 \cdot 8^{\star \dagger}$ & $38 \cdot 5 \pm 2 \cdot 4$ \\
\hline Bone surface/tissue volume & & & & \\
\hline$\left(\mathrm{mm}^{2} / \mathrm{mm}^{2} \times 10^{-3} /\right.$ day $)$ & $6 \cdot 2 \pm 0 \cdot 3$ & $6 \cdot 3 \pm 0 \cdot 6$ & $6 \cdot 9 \pm 0 \cdot 4$ & $6 \cdot 2 \pm 0 \cdot 4$ \\
\hline Bone formation rate/tissue volume (\%/day) & $0.09 \pm 0.02^{*}$ & $0.33 \pm 0.03^{\dagger}$ & $0 \cdot 11 \pm 0 \cdot 03^{*}$ & $0 \cdot 20 \pm 0 \cdot 02^{* \dagger}$ \\
\hline Bone formation rate/bone volume (\%/day) & $0 \cdot 28 \pm 0 \cdot 06^{*}$ & $0 \cdot 87 \pm 0 \cdot 14^{\dagger}$ & $0 \cdot 27 \pm 0 \cdot 08^{*}$ & $0 \cdot 52 \pm 0.05^{\star \dagger}$ \\
\hline $\begin{array}{l}\text { Bone formation rate/bone surface } \\
\left(\mu \mathrm{m}^{3} / \mu \mathrm{m}^{2} \text { per day }\right)\end{array}$ & $0.15 \pm 0.03 *$ & $0.45 \pm 0.07^{\dagger}$ & $0 \cdot 17 \pm 0 \cdot 05^{*}$ & $0.32 \pm 0.04^{* \dagger}$ \\
\hline Mineral apposition rate $(\mu \mathrm{m} /$ day $)$ & $1 \cdot 6 \pm 0 \cdot 1$ & $1 \cdot 9 \pm 0 \cdot 1$ & $1 \cdot 8 \pm 0 \cdot 1$ & $1 \cdot 7 \pm 0 \cdot 1$ \\
\hline Double-labeled surface/bone surface (\%) & $9 \cdot 5 \pm 1 \cdot 6^{*}$ & $27 \cdot 4 \pm 1 \cdot 4^{\dagger}$ & $8 \cdot 6 \pm 2 \cdot 0^{*}$ & $18 \cdot 1 \pm 2 \cdot 1^{* \dagger}$ \\
\hline
\end{tabular}


Table 5 Relative activity of $2-\mathrm{OHE}_{1}, 4-\mathrm{OHE}_{1}$ and $16 \alpha-\mathrm{OHE}_{1}$ as compared with $17 \beta$-estradiol. All values are percentages. Estrogen activity of $17 \beta$-estradiol treatment in the OVX rat was set at $100 \%$. The effects of the metabolites are expressed as a percentage of those observed for the $17 \beta$-estradiol treated groups relative to the OVX-vehicle group. Data for 2- and $16 \alpha-\mathrm{OHE}_{1}$ were obtained previously (Westerlind et al. 1998)

\begin{tabular}{|c|c|c|c|c|}
\hline & $2-\mathrm{OHE}_{1}$ & 4-OHE & $16 \alpha-\mathrm{OHE}_{1}$ & $17 \beta$-estradio \\
\hline \multicolumn{5}{|l|}{ Measurement } \\
\hline Body weight change & 18 & 66 & 63 & 100 \\
\hline \multicolumn{5}{|l|}{ Uterus } \\
\hline Wet weight & 0 & 50 & 36 & 100 \\
\hline Epithelial height & 0 & 32 & 26 & 100 \\
\hline Mammary gland proliferation* & 11 & 13 & 33 & 100 \\
\hline Longitudinal bone growth & 18 & 50 & 77 & 100 \\
\hline \multicolumn{5}{|l|}{ Cortical bone } \\
\hline Bone formation rate & -24 & 31 & 80 & 100 \\
\hline Mineral apposition rate & -21 & 52 & 65 & 100 \\
\hline \multicolumn{5}{|l|}{ Cancellous bone } \\
\hline Bone formation rate/bone surface & 23 & 46 & 75 & 100 \\
\hline Double-labeled surface/bone surface & 18 & 49 & 77 & 100 \\
\hline
\end{tabular}

4-OHE ${ }_{1}$ and it could be expected that the majority of increased cell proliferation would occur during the initial period of estrogen stimulus. At 3 weeks, it would be speculated that the glands had reached a new level of homeostasis.

Bone growth and turnover in $4-\mathrm{OHE}_{1}$-treated animals was intermediate between OVX and $\mathrm{E}_{2}$ treated-animals. Longitudinal growth rate was slowed and both cortical and cancellous turnover data indicate a decrease in the rate of bone formation. Thus 4-OHE 1 attenuated some of the OVX-induced changes but was not as efficacious as $E_{2}$. The effects of $4-\mathrm{OHE}_{1}$ are contrasted to $2-\mathrm{OHE}_{1}$ in the previous study (Westerlind et al. 1998) which had no effect on the bone and to $16 \alpha-\mathrm{OHE}_{1}$ which was nearly as effective as $\mathrm{E}_{2}$ in antagonizing OVX-induced changes in bone growth and turnover.

It is interesting to note that $4-\mathrm{OHE}_{1}$, a catechol estrogen metabolite, has significant estrogen activity whereas its counterpart, $2-\mathrm{OHE}_{1}$, has none. This may be a function of the relative binding affinity of the two metabolites for the estrogen receptor. 2-OHE ${ }_{1}$ has markedly reduced affinity (2\% of estradiol) for the receptor compared with 4-OHE 1 (11\% of estradiol) (Martucci \& Fishman 1979). The dissociation kinetics of $2-\mathrm{OHE}_{1}$ from the estrogen receptor are also much more rapid than 4- $\mathrm{OHE}_{1}$ (Barnea et al. 1983); shorter occupation time would result in a diminished estrogenic response. It is also noteworthy that methylation of C-4 estrogens does not appear to terminate their biological activity as occurs with the 2-hydroxyestrogens (Martucci 1983). Additionally, it has been reported recently that some of effects of the 4-hydroxyestrogens may be non-receptor mediated. Injection of the estrogen antagonist ICI 182780 resulted in abrogation of $17 \beta$-estradiol's increase of lactoferrin and progesterone receptor expression in the mouse uterus but had no effect on the increased expression resulting from 4-OHE 2 treatment (Das et al. 1998). Activity of the metabolites may also be a function of the absolute or relative presence of estrogen receptors $(\alpha, \beta$ or other) present in a given tissue.

Although 2-OHE ${ }_{1}$ is the major circulating catechol metabolite and the level of $4-\mathrm{OHE}_{1}$ is approximately $15-25 \%$ of $2-\mathrm{OHE}_{1}$ (Adlercreutz et al. 1989), it is important to consider that individual tissues have the ability to metabolize estrogens and that circulating levels may not be reflective of the effects at an organ or tissue level (Zhu \& Conney 1998). Liehr \& Ricci (1996) observed greater 4-hydroxylation in neoplastic breast tissue from breast cancer patients than in breast tissue from woman undergoing reduction mammoplasty. Interestingly, 4-hydroxylase levels were also elevated in the normal breast tissue from the breast cancer patients (Liehr \& Ricci 1996). These findings are similar to those that have been observed for $16 \alpha-\mathrm{OHE}_{1}$. 16 $\alpha$-Hydroxylation was higher in the terminal ductal lobular units in cancerous and non-cancerous tissues from women with breast cancer compared with women without breast cancer (Telang et al. 1991, Osborne et al. 1993).

Although $4-\mathrm{OHE}_{1}$ and $16 \alpha-\mathrm{OHE}_{1}$ may be more similar in action in the breast, $16 \alpha-\mathrm{OHE}_{1}$ was profoundly more estrogenic on the bone than $4-\mathrm{OHE}_{1}$ - a factor that would suggest its potential role in osteoporosis pathogenesis. Data are beginning to emerge in small clinical studies that elevated $16 \alpha$-hydroxylation is associated with greater bone mineral density and a reduced rate of bone loss at menopause (Hodge et al. 1995, Lim et al. 1997).

Table 5 provides a summary of the relative activity of $2-$ and $16 \alpha-\mathrm{OHE}_{1}$ (previously evaluated (Westerlind et al. 1998)) and 4-OHE 1 . The relative estrogen action of each metabolite is expressed as a percentage of OVX'd animals 
response to $\mathrm{E}_{2}$ treatment compared with the vehicletreated OVX group. The difference in response between the OVX-vehicle and OVX- $\mathrm{E}_{2}$-treated group is set at $100 \% .2-\mathrm{OHE}_{1}$ resulted in little to no estrogen action on the measurements evaluated. $4-\mathrm{OHE}_{1}$ displayed significant estrogen action on body weight and more moderate estrogen activity in the uterus, mammary gland and bone. $16 \alpha-\mathrm{OHE}_{1}$ had more marked estrogen action on the bone than either of the other two metabolites and had strong action on body weight. $16 \alpha-\mathrm{OHE}_{1}$ had moderate estrogenic effects on the uterus and mammary gland.

In conclusion, $4-\mathrm{OHE}_{1}$ had tissue-selective activity on the uterus, mammary gland, liver and bone. Its profile of activity was significantly different from the primary circulating catechol metabolite, $2-\mathrm{OHE}_{1}$. The differential effects of the two catechol metabolites on estrogensensitive tissues warrants consideration as investigators attempt to increase catechol estrogen metabolism to decrease the risk of diseases such as breast cancer.

\section{References}

Adlercreutz H, Fotsis T, Hockerstedt K, Hamalainen E, Bannwart C, Bloigu S, Valtonen A \& Ollus A 1989 Diet and urinary estrogen profile in premenopausal omnivorous and vegetarian women and premenopausal women with breast cancer. Journal of Steroid Biochemistry and Molecular Biology 34 527-530.

Ball P \& Knuppen R 1980 Catecholoestrogens (2- and 4-hydroxyestrogens): chemistry, biogenesis, metabolism, occurrence and physiological significance. Acta Endocrinologica 232 1-127.

Barnea ER, MacLusky NJ \& Naftolin F 1983 Kinetics of catechol estrogen-estrogen receptor dissociation: a possible factor underlying differences in catechol estrogen biological activity. Steroids $\mathbf{4 1}$ 643-656.

Das SK, Tan J, Johnson DC \& Dey SK 1998 Differential spatiotemporal regulation of lactoferrin and progesterone receptor genes in the mouse uterus by primary estrogen, catechol estrogen, and xenoestrogen. Endocrinology 139 2905-2915.

Evans GL, Bryant HU, Magee D, Sato M \& Turner RT 1994 The effects of raloxifene on tibia histomorphometry in ovariectomized rats. Endocrinology 134 2283-2288.

Evans GL, Bryant HU, Magee DE \& Turner RT 1996 Raloxifene inhibits bone turnover and prevents further cancellous bone loss in adult ovariectomized rats with established osteopenia. Endocrinology 137 4139-4144.

Ho GH, Luo XW, Ji CY, Foo SC \& Ng GH 1998 Using 2/16 alpha-hydroxyestrone ration: correlation with serum insulin-like growth factor binding protein-3 and a potential biomarker of breast cancer risk. Annals of the Academy of Medicine, Singapore 27 294-299.

Hodge J, Roodman-Weiss J, Lyss C, Wagner D, Klug T \& Civitelli R 1995 Increased inactive estrogen metabolites in urine of early postmenopausal women with low bone density. Journal of Bone and Mineral Research 10 S444.

Jiminez MA, Magee DE, Bryant HU \& Turner RT 1997 Clomiphene prevents bone loss from tibia of ovariectomized rats. Endocrinology 138 1794-1800.

Kabat GC, Chang CJ, Sparano JA, Sepkovic DW, Hu XP, Khalil A, Rosenblatt R \& Bradlow HL 1997 Urinary estrogen metabolites and breast cancer: a case control study. Cancer Epidemiology Biomarkers and Prevention 6 505-509.
Ke HZ, Simmons HA, Pirie CM, Crawford DT \& Thompson DD 1995 Droloxifene, a new estrogen antagonist/agonist, prevents bone loss in ovariectomized rats. Endocrinology 136 2435-2441.

Liehr JG 1994 Mechanism of metabolic activation and inactivation of catechol estrogens: a basis of genotoxicity. Polycyclic Aromatic Compounds 6 229-239.

Liehr JG \& Ricci MJ 1996 4-hydroxylation of estrogens as markers of human mammary tumors. PNAS 93 3294-3296.

Lim SK, Won YJ, Lee JH, Kwon SH, Lee EJ, Kim KR, Lee HC, Hah KB \& Chung BC 1997 Altered hydroxylation of estrogen in patients with postmenopausal osteopenia. Journal of Clinical Endocrinology and Metabolism 82 1001-1006.

Martucci CP 1983. The role of 2-methoxyestrone in estrogen action. Journal of Steroid Biochemistry and Molecular Biology 19 635-638.

Martucci CP \& Fishman J 1979 Impact of continuously administered catechol estrogens on uterine growth and luteinizing hormone secretion. Endocrinology 105 1288-1292.

Meilahn EN, DeStavola B, Allen DS, Fentiman I, Bradlow HL, Sepkovic DW \& Kuller LH 1998 Do urinary oestrogen metabolites predict breast cancer? Guernsey III cohort follow-up. British Journal of Cancer 78 1250-1255.

Osborne MP, Bradlow HL, Wong GYC \& Telang NT 1993 Upregulation of estradiol C16 $\alpha$-hydroxylation in human breast tissue: a potential biomarker of breast cancer risk. Journal of the National Cancer Institute 85 1917-1920.

Schneider J, Kinne D, Fracchia A, Pierce V, Anderson KE, Bradlow HL \& Fishman J 1982 Abnormal oxidative metabolism of estradiol in women with breast cancer. PNAS 79 3047-3051.

Sepkovic DW, Bradlow HL, Ho G, Hankinson SE, Gong L, Osborne MP \& Fishman J 1995 Estrogen metabolite ratios and risk assessment of hormone related cancers: assay validation and prediction of cervical cancer risk. Annals of the New York Academy of Sciences 768 312-316.

Telang NT, Axelrod DM, Wong GY, Bradlow HL \& Osborne MP 1991 Biotransformations of estradiol explant culture of human mammary tissue. Steroids 56 37-43.

Turner RT, Vandersteenhoven JJ \& Bell NH 1987 The effects of ovariectomy and $17 \beta$-estradiol on cortical bone histomorphometry in growing rats. Journal of Bone and Mineral Research 2 61-66.

Turner RT, Wakley GK, Hannon KS \& Bell NH 1988 Tamoxifen inhibits osteoclast-mediated resorption of trabecular bone in ovarian hormone-deficient rats. Endocrinology 122 1146-1150.

Westerlind KC, Wakley GK, Evans GL \& Turner RT 1993 Estrogen does not increase bone formation in growing rats. Endocrinology 133 2924-2934.

Westerlind KC, Gibson KJ, Malone P, Evans GL \& Turner RT 1998 Differential effects of estrogen metabolites on bone and reproductive tissues of ovariectomized rats. Journal of Bone and Mineral Research 13 1023-1031.

Wronski TJ, Walsh CC \& Iganszewski LA 1986 Histological evidence for osteopenia and increased bone turnover in ovariectomized rats. Bone 7 119-123.

Wronski TJ, Cintron M \& Dann LM 1988 Temporal relationship between bone loss and increased bone turnover in ovariectomized rats. Calcified Tissue Research 43 179-183.

Yager JD \& Liehr JG 1996 Molecular mechanisms of estrogen carcinogenesis. Annual Review of Pharmacology and Toxicology 36 203-232.

Zhu BT \& Conney AH 1998 Functional role of estrogen metabolism in target cells: review and perspectives. Carcinogenesis 19 1-27.

Received 18 April 2000

Revised manuscript received 11 July 2000

Accepted 26 July 2000 